\title{
Water and Sanitation Situation in Selected Villages in Ifedore Local Government Area of Ondo State, Nigeria
}

\author{
Rotowa O. O.* and Adeleye O. \\ Department of Urban and Regional Planning, Federal University of Technology, Akure, Nigeria \\ Corresponding Author: *oorotowa@futa.edu.ng
}

https://doi.org/10.36263/nijest.2021.02.0298

\begin{abstract}
Water is essential for life, while sanitation is for dignity. Worldwide, Nigeria is second to India in term of open defecation, with an estimated population of 109 million open defecators. The rural areas currently lagged behind the urban areas in term of water and sanitation. A survey of two villages in the Ifedore Local Government of Ondo State, Nigeria was conducted, using 88 respondents selected through purposive sampling technique from Ikota and Aaye village cluster. Findings from the study revealed that sources of water are boreholes, wells and streams. On the other hand, most of the indigenes still practice open defecation, though some of them use water closet, pour flush toilet and variances of pit latrine as toilet. Most of them still expect the government to install and maintain facilities provided. It is suggested that demand driven and the bottom-top approach where the people first believe that water and sanitation prevent diseases and provide longevity be explored. It is believed that reinventing the services of sanitary officers (Wole Wole), will help in disseminating and enforcing proper hygienic practices.
\end{abstract}

Keywords: Water, Sanitation, Ifedore, Villages, Culture

\subsection{Introduction}

Water is one of the most valuable natural resources vital to the existence of any form of life. It constitutes an essential element of life (Olajuyigbe and Fasakin, 2010). An adequate supply of safe, clean water is the most important precondition for sustaining human life, for maintaining ecosystems that support all life and for achieving sustainable development (Topfer as cited in Olajuyigbe and Fasakin, 2010). Access to safe drinking water is considered a precondition for health and for success in the fight against poverty, hunger, child deaths and gender inequality (WHO/UNICEF, 2017).

The entire history of mankind could be written in terms of man's need for water. Early civilization flourished along river valleys where there was abundant water to support life. Clean water is an essential element for human health, wellbeing and prosperity, whether used for drinking, cleaning, food production or industrial output (Ritchie and Roser, 2019). Access to adequate water resources is a basic human need, likewise access to sufficient and safe sanitation facilities as it is vital for hygiene, disease prevention, and human health (Ritchie and Roser, 2019; UN-Water, 2019). Water and sanitation are crucial to sustain life and health and fundamental to the dignity of all (Kaashif, 2019).

Improved drinking water refers to water sourced from a tap located within the premises, a public stand pipe, a tube-well, a protected dug well or spring, and rainfall (UNICEF/WHO, 2015). According to Lukman et al. (2016) access to drinking water is measured by the number of people who have a realistic means of getting an adequate (quality and quantity) amount of water that is safe for drinking, washing and essential household activities. Adequate access to potable water means that women and children will spend limited time in fetching water that could be used actually for drinking, cooking and other tasks (Ishaku et al., 2011). Ishaku et al. (2011) added that water is a vital component in poverty alleviation efforts and reflects the health and sanitation of people in the country. 
Sanitation is a basic human right, in spite of this; about 2.4 billion people lack access to adequate sanitation facilities (WHO/UNICEF, 2015). Sanitation is a system that promotes the appropriate disposal of human and animal waste for improving and protecting public and environmental health (UNICEF/WHO, 2015). An improved sanitation facility is that, which hygienically separates excreta from human contacts, and is used by only members of one household. These include toilets flushing to sewer systems or septic tanks, ventilated improved pit (VIP) latrines, pit latrines with a slab, and composting toilets. Aigbiremolen et al. (2018) pointed out that adequate sanitation facilities are essential to the health and socioeconomic well-being of households, communities, and the entire society at large.

Improving public access to adequate drinking water and sanitation services is an increasingly important, yet challenging issue for governments, international development agencies, urban planners, water sector organizations, and sanitation practitioners, more particularly in nations with fast growing populations (Abubakar, 2017; Abubakar, 2019). Today, 2.2 billion people lack access to safely manage drinking water services. This, coupled with the 2.4 billion people that lack safely managed sanitation services and unsafe hygiene practices, has a compounding effect on people's health (WHO/UNICEF, 2019).

UN-Water (2019) pointed out that People who are mostly affected by inadequate access to water and sanitation resides in rural areas. These people in the rural areas are without access to improved drinking water, such as water from a protected borehole well or municipal piped supply. Hence, they are forced to rely on water sources that are not improved, such as surface water, unprotected and possibly contaminated wells, or vendors selling water of unverifiable sources and quality. For many communities in rural areas, water sources are usually far from their homes. Women and girls spend much of their time and energy fetching water, a task which often exposes them to risk of attack from men and even wild animals (UN-Water, 2019).

People without access to improved sanitation are left with no option but to use inadequate communal latrines or to practice open defecation. Faecal matter is transferred back into people's food and water resources, helping to spread serious diseases such as cholera, typhoid, dengue, etc. The impacts of inadequate water and sanitation on child mortality rates is devastating, with more than 297,000 children under five deaths recorded annually from diarrheal diseases due to poor sanitation, poor hygiene, or unsafe drinking water. The extent of damage experienced is felt more by rural inhabitants, children, women and urban slum dwellers (WHO/UNICEF, 2015). In rural regions where most poor people are domiciled, access to safe water seems to be abhorrent, leaving them with no option, than to depend solely on unprotected wells, and surface streams/rivers which are susceptible to pollution (World Bank, 2001; UN-Water, 2019).

Before the commencement of Sustainable Development Goals (SDGs) in 2015, only 39\% of the global population used adequate sanitation facilities and more than one billion practiced open defecation (OD), mostly in rural areas of low- and middle-income countries (Novotný et al., 2018). Sinha et al. (2018) pointed out that monitoring of sanitation programs in rural areas is always restricted to sanitation access and coverage, with little emphasis on the use of the facilities despite increasing evidence of widespread non-use. According to Sinha et al. (2018), people with access to latrines do not all use the facilities, suggesting that latrine coverage does not necessarily translate into use. Sinha et al. (2018) further pointed out that one of the reasons for non-use of sanitation facilities is preference for open defecation. This study, therefore, seeks to examine water and sanitation situation among rural households in the Ifedore Local Government Area of Ondo State, Nigeria.

\subsection{Methodology}

The study was carried out at Ikota and Aaye village clusters in Ifedore Local Government Area (LGA) of Ondo State, Nigeria (see Figures 1 and 2). The headquarters of Ifedore LGA, is at Igbara Oke (Finelib, 2018). Ifedore LGA lies between latitude $7^{\circ} 23^{\prime}$ North of the Equator and on the longitude $5^{\circ} 5^{\prime}$ East of the Greenwich Meridian (see Figure 2). The 2006 population census puts the population of the area at 176,327 , however, using a growth rate of $3.2 \%$, the present population (2019) is estimated at 265,555 . Ifedore has an area of $295 \mathrm{~km}^{2}$ and a generally flat and undulating 
terrain and climatic features synonymous to that of Akure South, Local Government (City Population, 2017). As a result, Ifedore enjoys a tropical season (April-October) and the dry season (NovemberMarch). The Local Government Area lies in the rain forest zone with mean annual rainfall between $1300-1600 \mathrm{~mm}$ and with average temperatures between $27.5^{\circ} \mathrm{C}-32.5^{\circ} \mathrm{C}$. The relative humidity ranges between $85 \%$ and $100 \%$ during the rainy season and less than $60 \%$ during dry season. The residents of Ifedore depend on boreholes, taps, wells and surface water such as Stream and River sources for their domestic activities and for consumption. The majority of the inhabitants of Ifedore are agrarian, though part of the populace also engages in trading and some in the civil service.

This research is descriptive in nature; it employed qualitative and quantitative research methods using oral interview and a well-structured questionnaire to elicit information on choice of water sources and sanitation systems in selected villages in the study area. The study area was mapped out with the aid of Google Earth software and digitized on Arc GIS.

Purposive sampling was employed to select two villages of Ikota and Aaye. This is because the inhabitants of the LGA share many things in common such as, same ethnic grouping, language, occupation; therefore, the sample size is their true reflection. The villages considered in the study has about eight hundred people, out of which ten percent which is eighty-eight (88) household heads were selected for this study. The buildings in the selected villages (Ikota and Aaye) were determined with the aid of satellite imagery of Ifedore, obtained from Google Earth supported with ground truthing as shown on Figures 1 and 2.

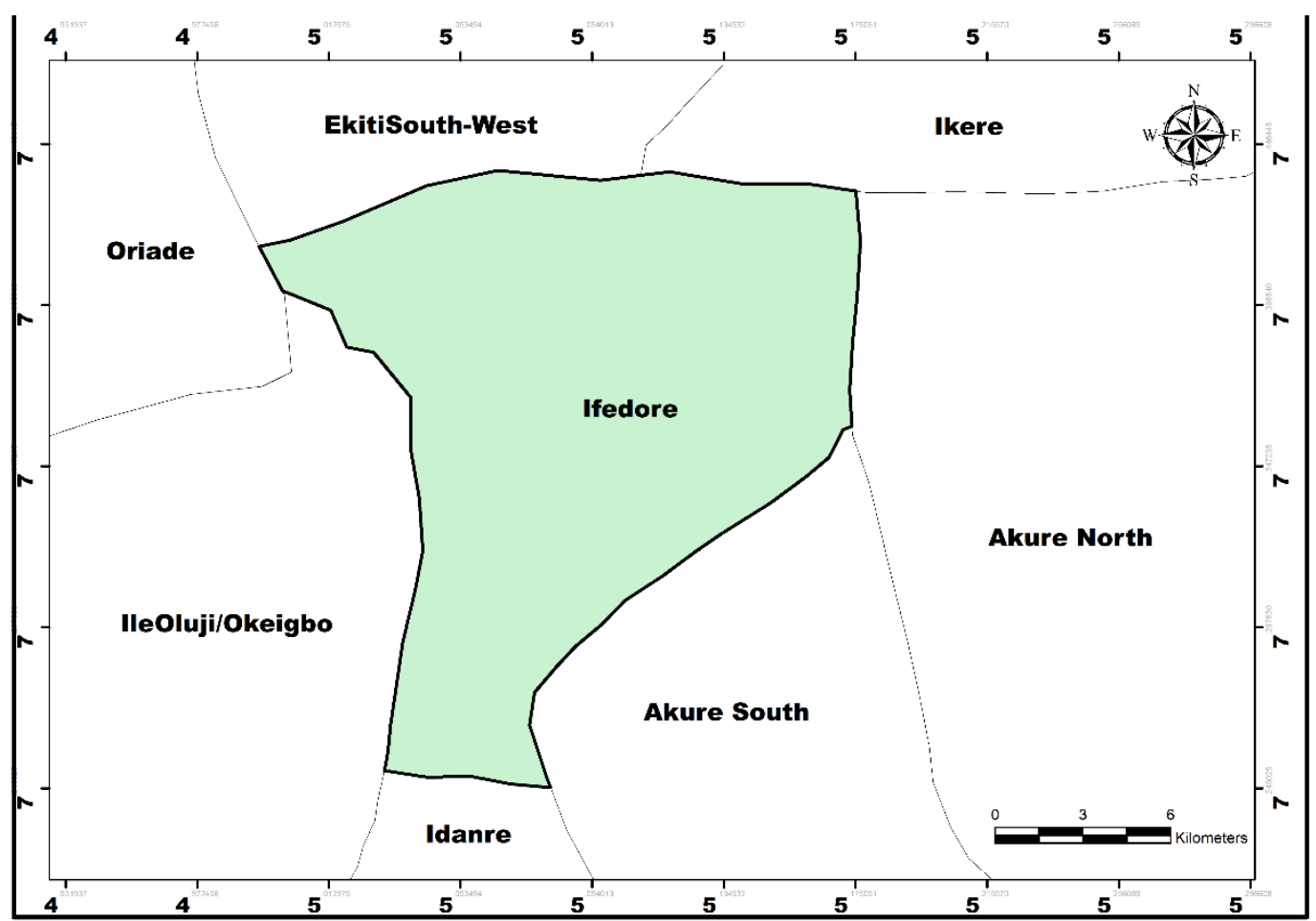

Figure 1: Map of Ifedore Local Government Area, Ondo State, Nigeria Source: GIS Map Extract, 2019 


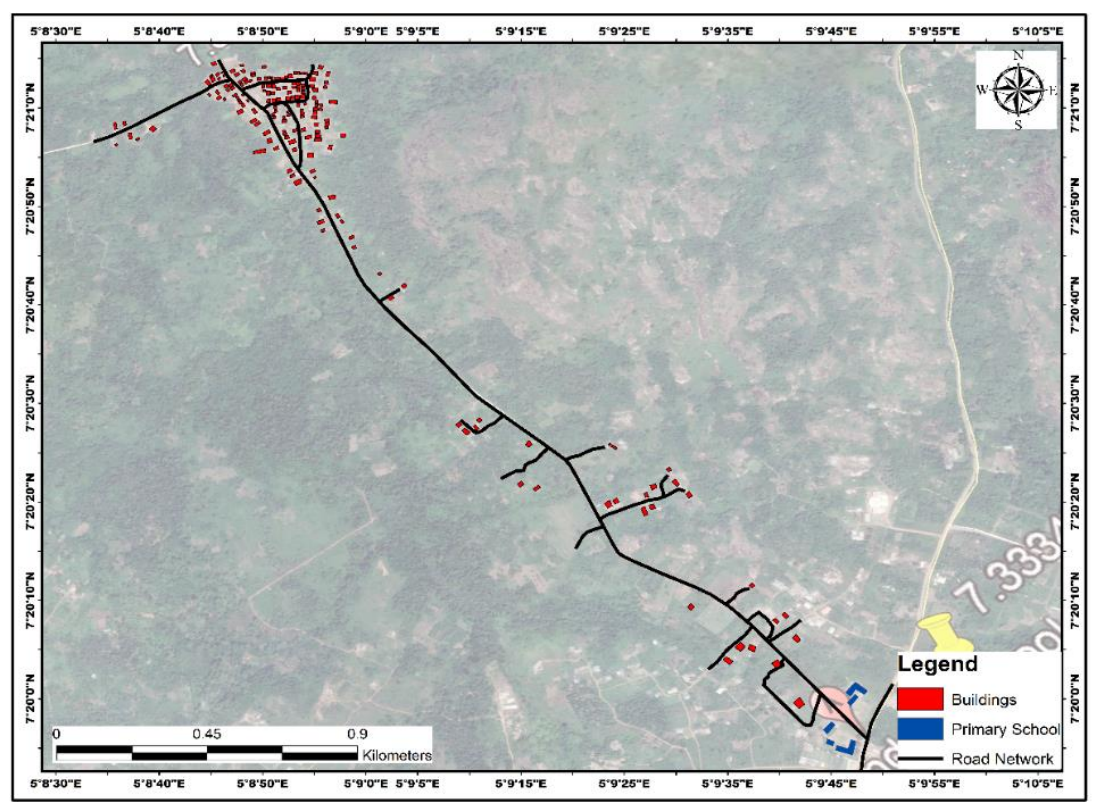

Figure 2: Map showing Aaye and Ikota Villages, Ifedore LGA, in Ondo State. Source: Fieldwork, 2019

\subsection{Results and Discussions}

\subsection{Sex of respondents}

Based on the findings from the field investigation, the majority of the respondents that participated in the study were females constituting about $58.0 \%$ of the sample while males constituted the other $42 \%$ as illustrated in Table 1 . This revealed that the responsibility of collecting, managing and usage of water for domestic needs fall majorly on females within a household in the two villages.

Table 1: Sex of respondents

\begin{tabular}{llc}
\hline Respondents & Frequency & Percentage (\%) \\
\hline Male & 37 & 42.0 \\
Female & 51 & 58.0 \\
\hline Total & 88 & 100 \\
\hline \multicolumn{3}{r}{ Source: Fieldwork, 2019}
\end{tabular}

\subsection{Age of respondents}

The target population also cuts across all the age groups in the two villages. Analysis of the data obtained from field revealed that about $30.7 \%$ of the respondents in this research were above 50 years, indicating that the majority of the residents were old people. Respondents between age 36-50 years and 26-35 years accounted for $25.0 \%$ and $19.3 \%$ respectively. While the age group of between 18-25 years constituted about $9.1 \%$ of the total population sampled, respondents below 18 years constituted $15.9 \%$. This explained why bulk of the resident was farmers and had no formal education. From these findings, it can be inferred that cultural factors still strongly influence sanitation practices in the villages. The age distribution of the respondents is shown in Table 2.

Table 2: Age of respondents

\begin{tabular}{lll}
\hline Age & Frequency & Percentage (\%) \\
\hline Below 18yrs & 14 & 15.9 \\
18-25yrs & 8 & 9.1 \\
26-35yrs & 17 & 19.3 \\
36-50yrs & 22 & 25.0 \\
50yrs above & 27 & 30.7 \\
\hline Total & 88 & 100 \\
\hline \multicolumn{3}{c}{ Source: Fieldwork, 2019}
\end{tabular}




\subsection{Marital status of respondents}

Findings showed that $36.4 \%$ of the respondents were single, $44.3 \%$ of the respondents were married, while $3.4 \%$ were divorced, widows and widowers constituted $9.1 \%$ and $6.8 \%$ respectively. This is depicted in Table 3.

Table 3: Marital status of respondents

\begin{tabular}{lll}
\hline Marital Status & Frequency & Percentage (\%) \\
\hline Single & 32 & 36.4 \\
Married & 39 & 44.3 \\
Divorced & 3 & 3.4 \\
Widow & 8 & 9.1 \\
Widower & 6 & 6.8 \\
\hline Total & 88 & 100 \\
\hline \multicolumn{3}{c}{ Source: Fieldwork, 2019}
\end{tabular}

\subsection{Household size of respondents}

Table 4 illustrates that larger percentage of the families in the villages had household size of 4 and above people accounting for about $78.4 \%$ of the total population. The study revealed that only $21.6 \%$ of the households surveyed had between 1-3 people. The implication of this is that majority of the households in the villages required more water for domestic use, and this certainly puts more pressure on the existing water facilities. The qualitative portion of this study also revealed that the toilet facility in majority of the families with larger household size was inadequate, which may force some of the members to defecate in the open when other members of the family are using the toilet available. The large size of the households in the villages maybe influenced by the need to have more family members who can provide labour for farming and related work.

Table 4: Household size of respondents

\begin{tabular}{lll}
\hline Respondents & Frequency & Percentage (\%) \\
\hline Between 1-3 & 19 & 21.6 \\
Between 4-6 & 44 & 50.0 \\
7 and above & 25 & 28.4 \\
\hline Total & 88 & 100 \\
\hline \multicolumn{3}{c}{ Source: Fieldwork, 2019}
\end{tabular}

\subsection{Educational qualification of respondents}

Knowledge is acquired through learning, and since learning has to do with education, the study sought to get the educational qualification of the respondents. From table 5, it is evident that high proportions of the respondents constituting about $39.8 \%$ of the total population surveyed had received no formal education. Findings revealed that the majority of the respondents had primary school education which constituted about $27.3 \%$ of the sampled population. This was followed by those who completed secondary school representing about $20.5 \%$. Only $12.5 \%$ went through tertiary education.

The level of education and literacy to a large extent help to know and understand the importance of using a particular water source or practicing a certain sanitation behaviour.

Table 5: Educational qualification of the respondents

\begin{tabular}{lll}
\hline Educational qualification & Frequency & Percentage (\%) \\
\hline No Schooling & 35 & 39.8 \\
Primary Education & 24 & 27.3 \\
Secondary Education & 18 & 20.5 \\
Tertiary Education & 11 & 12.5 \\
\hline Total & 88 & 100 \\
\hline \multicolumn{3}{c}{ Source: Fieldwork, 2019 }
\end{tabular}




\subsection{Average monthly income of respondents}

Affordability is one's ability to pay for a sanitation facility or service or to engage in a sanitation behaviour. And since income is one of the factors that influence affordability, the study sought to get an average monthly income of the respondents.

Findings revealed that $34.1 \%$ of the respondents earned below $\$ 18,000$ monthly. Until recently, $\$ 18,000$ was the minimum wage for people employed by the government of the Federal Republic of Nigeria. Further findings showed that $33.0 \%$ of the respondents earned between $\$ 18,000$ to $\$ 36,000$ monthly, while $22.7 \%$ of them earned between $\$ 37,000$ to $\$ 54,000$ monthly. Also, $5.7 \%$ earned between $\$ 55,000$ to $\$ 72,000$ and only $4.5 \%$ earned above $\$ 72,000$ as depicted in Table 6 . People in this area are agrarian, instead of investing in water and sanitation, preference is more on farming. The cumulative effect was a wide usage of unimproved sanitation facilities and dependence on public water facilities provided by the government.

Table 6: Monthly income of respondents

\begin{tabular}{|c|c|c|}
\hline Income $(\AA)$ & Frequency & Percentage $(\%)$ \\
\hline Below 18,000 & 30 & 34.1 \\
\hline Between $18,000-36,000$ & 29 & 33.0 \\
\hline Between 37,000-54,000 & 20 & 22.7 \\
\hline Between 55,000-72,000 & 5 & 5.7 \\
\hline Above 72,000 & 4 & 4.5 \\
\hline Total & 88 & 100 \\
\hline
\end{tabular}

\subsection{Occupation of respondents}

The study went further to seek to know the occupation (which to a large extent determines one's income) of the respondents. It was revealed from the findings that about $36.4 \%$ of the household respondents were farmers, $22.7 \%$ were traders, while $9.1 \%$ were civil servants, and $14.8 \%$ were artisans while, $14.8 \%$ were unemployed. The high proportion of farmers in the villages explains why a majority of the inhabitants had large household size and earned below $\$ 18,000$. Also, with the bulk of the respondents being agrarian, and majority of them (represented by 95.5\%) earning below $\$ 73,000$ monthly, the areas can be said to be typical rural areas. The occupation of the respondents is shown in Table 7.

Table 7: Occupation of the respondents

\begin{tabular}{lll}
\hline Occupation & Frequency & Percentage $(\%)$ \\
\hline Farmer & 32 & 36.4 \\
Trader & 20 & 22.7 \\
Civil servant & 8 & 9.1 \\
Artisan & 15 & 17.0 \\
Unemployed & 13 & 14.8 \\
\hline Total & 88 & 100 \\
\hline \multicolumn{3}{c}{ Source: Fieldwork, 2019}
\end{tabular}

\subsection{Sources of water supply in the area}

Access to water can be divided into two namely when residents were at home and when they are away to farm and places of work. Findings from respondents while at home revealed that the majority of the inhabitants of the villages constituting $35 \%$ obtained water from community borehole, $32 \%$ from hand dug well, 20\% through private tap and 13\% from stream/river as shown in Figure 3 . This revealed that the bulk of the population (about 87\%) had access to improved water. Well water source was included as part of the improved water sources because it was observed during the field survey that the well water sources in these villages were covered dug wells and not unprotected wells as depicted in Figure 5. Suffice to mention that if water access while away from home was examined, the result would have varied. This is because most of the boreholes and wells were provided by the government programmes on rural development. 


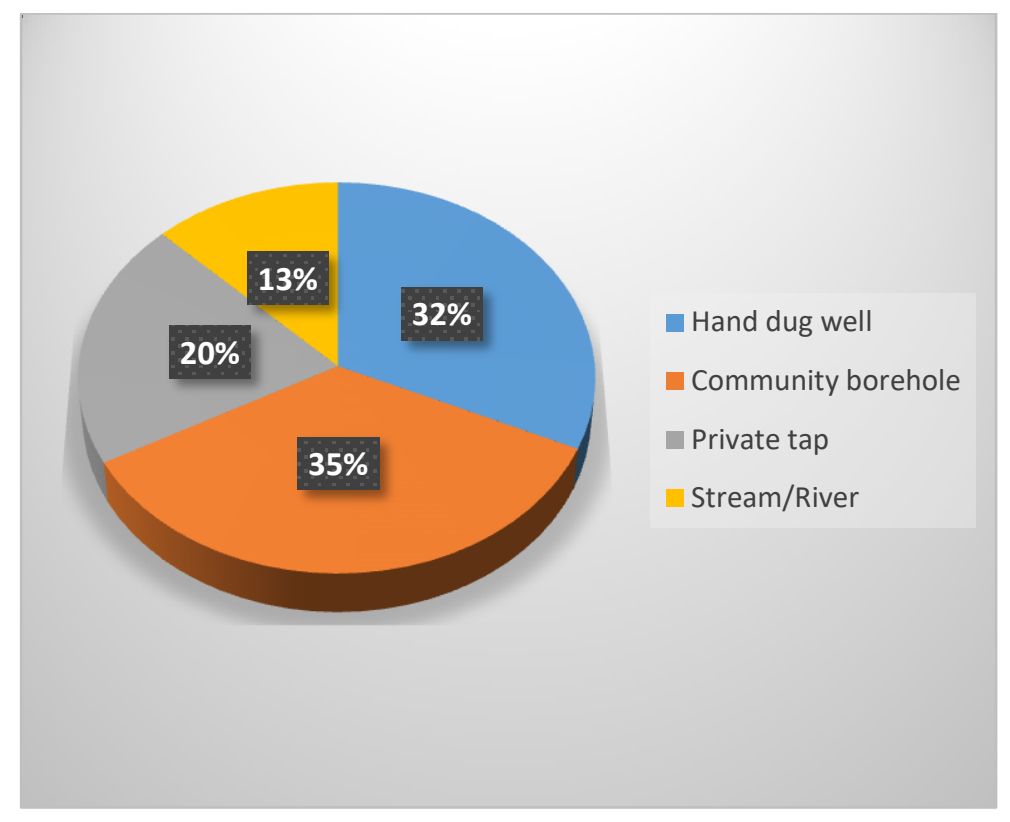

Figure 3: Sources of water supply in the villages Source: Fieldwork, 2019

It was discovered from the oral interviews with some of the respondents that most of the households in the villages stopped getting water from unimproved water sources (especially from "Eripo abuwemo" stream) since the interventions of the government and corporate organizations (a Quarry Company and Muslim Society) by providing community boreholes. One of the respondents from Ikota village indicated that some of the community boreholes were provided during Olusegun Mimiko's administration.

The provision of these community boreholes had given the residents of these villages opportunity to access improved water source and in a way may have motivated some of the households (especially those closer to the boreholes) to embrace improved sanitation facilities. The sources of water in the villages are depicted in Figure 4-7.

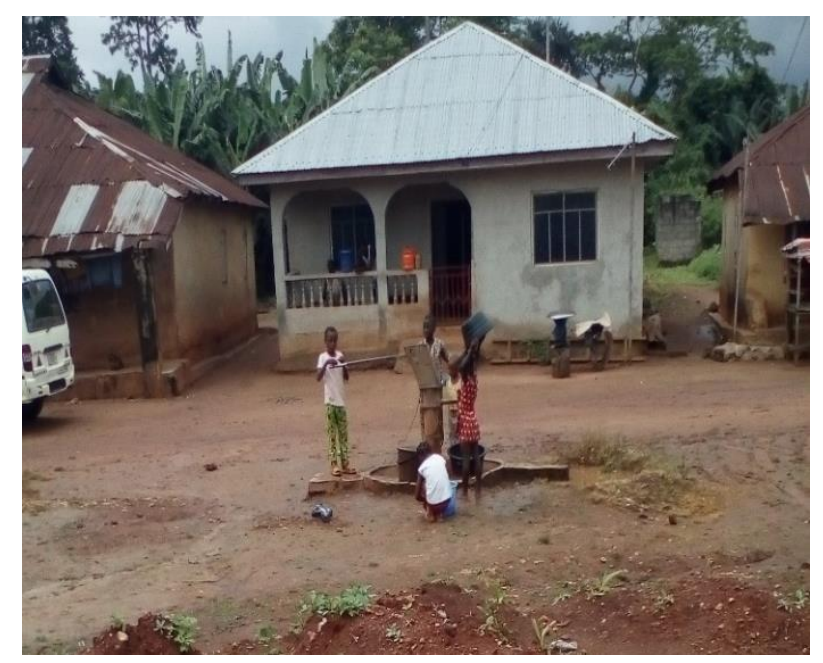

Figure 4: One of the community boreholes provided by the Government in Ikota village Source: Fieldwork, 2019

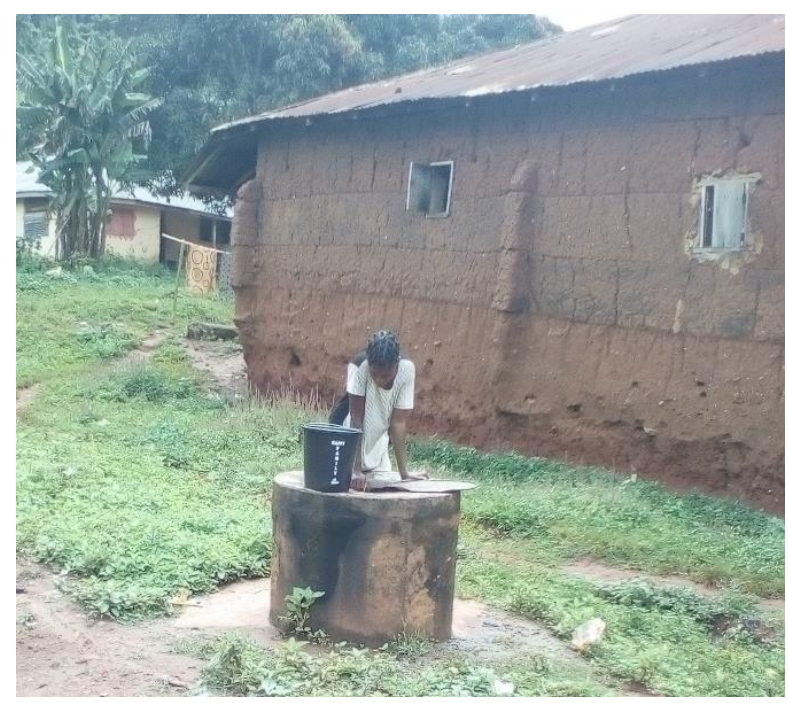

Figure 5: Hand dug well water source at Ikota village

Source: Fieldwork, 2019 


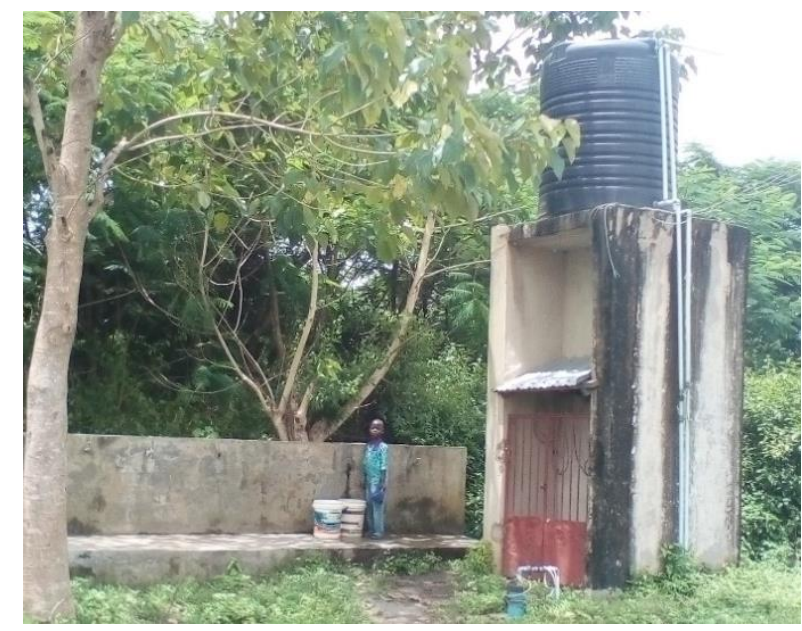

Figure 6: Borehole with water storing tank and taps for collecting water in Aaye village Source: Fieldwork, 2019

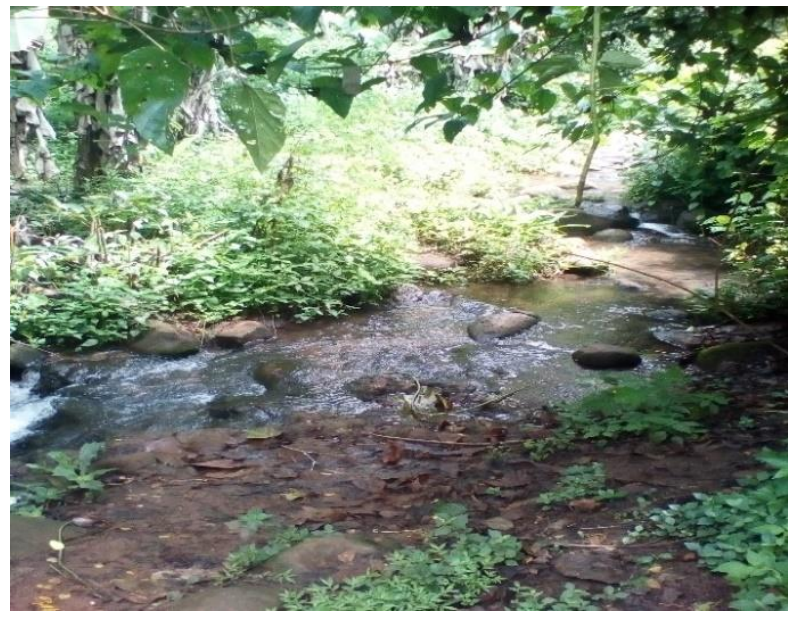

Figure 7: "Eripo Abuwemo" stream in Ikota village

Source: Fieldwork, 2019

Although it could be inferred from Figure 4 to 7, that the villages had access to some water sources. However, the bulk of the respondents, constituting about $76.1 \%$ indicated that the water obtained from the sources cannot be approved as potable. This is because the water needs to be treated before consumption. Therefore, only $23.9 \%$ claimed that the water is good for household uses, as shown in Figure 8 .

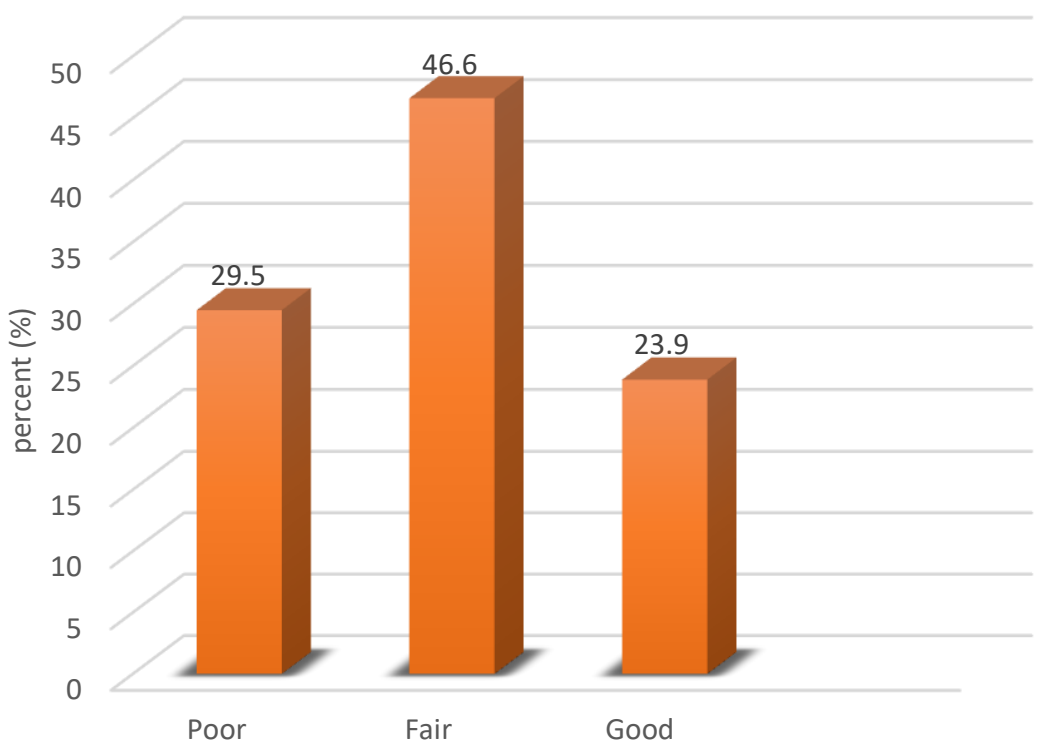

Figure 8: Quality of water Source: Fieldwork, 2019

The bad condition of the water quality in the villages could be linked to the fact that the majority of the water is not treated by the Ondo State Water Corporation, due to the remoteness and distance from their headquarters. Findings as shown in Table 8 revealed that about $70.5 \%$ of the households indicated that they do not treat their water before use. Only $29.5 \%$ of the respondents claimed that they apply some type of treatment of their water before consumption, in most cases they use only Alum.

Table 8: Treatment of water

\begin{tabular}{lll}
\hline Treatment by respondents & Frequency & Percentage $(\%)$ \\
\hline Yes treat water & 37 & 29.5 \\
No I do not treat water & 51 & 70.5 \\
\hline Total & 88 & 100 \\
\hline
\end{tabular}

Source: Fieldwork, 2019 
The study also sought to know the type of toilet facility available in households' building. Findings from the research showed that about $29 \%$ of the households surveyed had Pit latrine without slab toilet, $17 \%$ had Pit latrine with slab, while $13 \%$ and $8 \%$ had a flush toilet and water closet respectively, 33\% did not have a toilet. This implies that these 33\% of the households resort to open defecation in the management of their excreta.

It should be highlighted that the availability of a toilet facility in a home does not stop open defecation in the villages, because it was discovered that open defecation is not only practiced by people with no toilet facility as one of the respondents indicated that all residents (including those that have toilet facilities at home) defecate in the open while on the farm or when they are not at home. When asked for the reasons, they claimed that after leaving home, there is no way they can help it when they are pressed with nature. Although the adults claimed to dig holes and cover it after defecating, this is not the case with the children. Figure 9 depicts the types of toilets used by households.

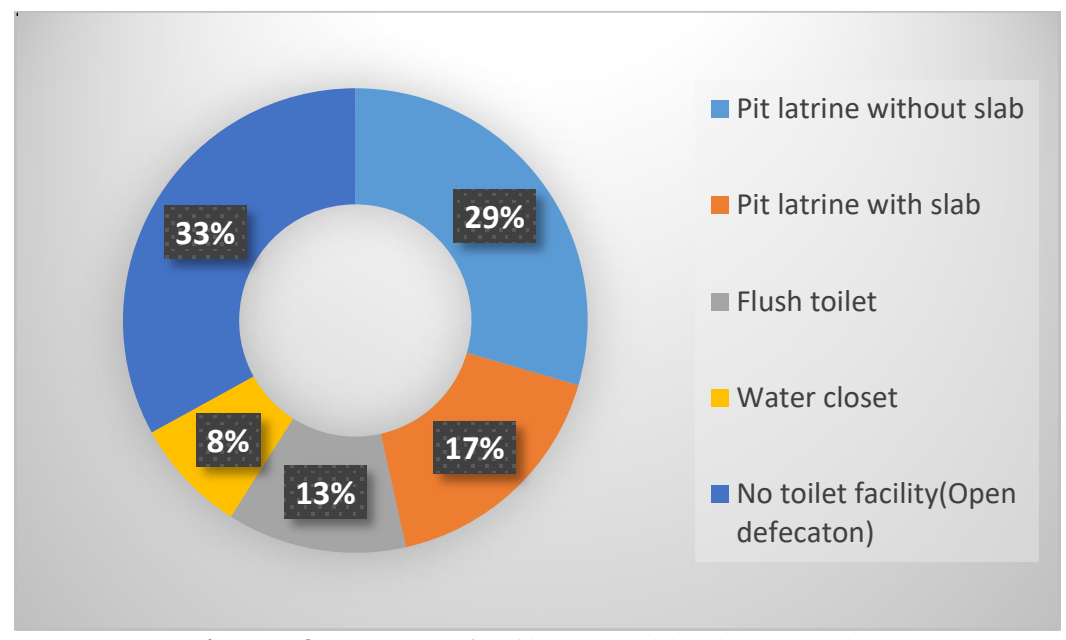

Figure 9: Types of toilets used by households. Source: Fieldwork, 2019

Findings from the study further showed that the majority of the inhabitants did not see anything bad defecating in the open as $71 \%$ of the respondent agreed that open defecation is harmless. Only a few of the respondents constituting about $29 \%$ agreed that it is unsafe to defecate in the open as depicted in Figure 10. This implies that the people are yet to appreciate the relevance of the health and hygiene impact of a toilet facility. Therefore, there is no sanction against open defecation in the villages.

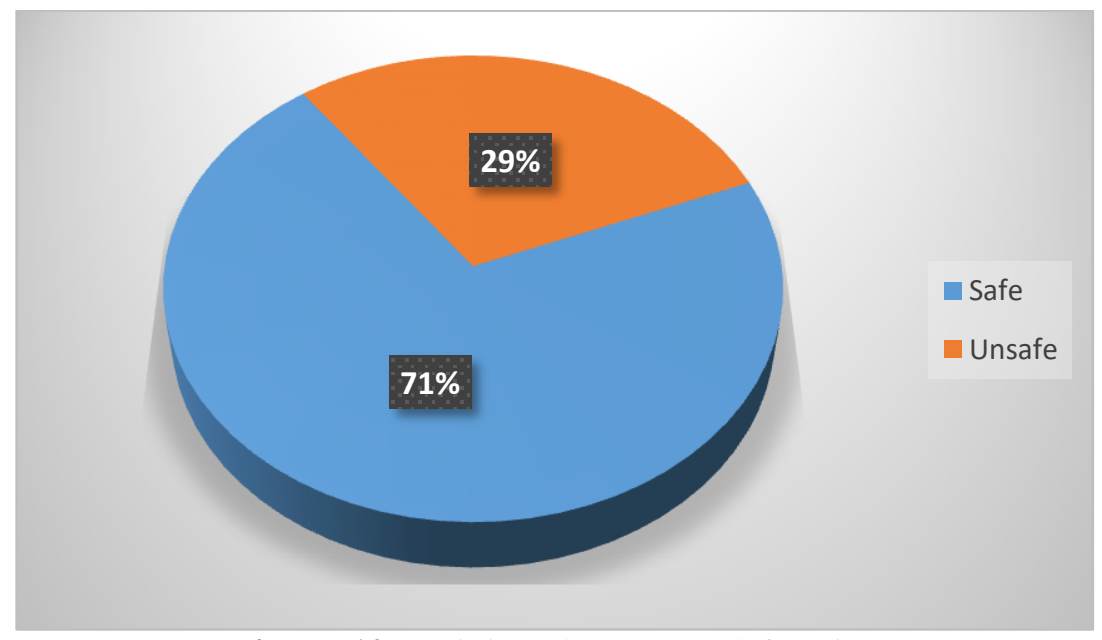

Figure 10: Opinion about open defecation Source: Fieldwork, 2019 
Although the majority of the inhabitants claimed to wash their hands after using toilet/defecating, however, just $33 \%$ claimed to wash their hands with water and soap. While the remaining $67 \%$ only used water. This is illustrated in Figure 11.

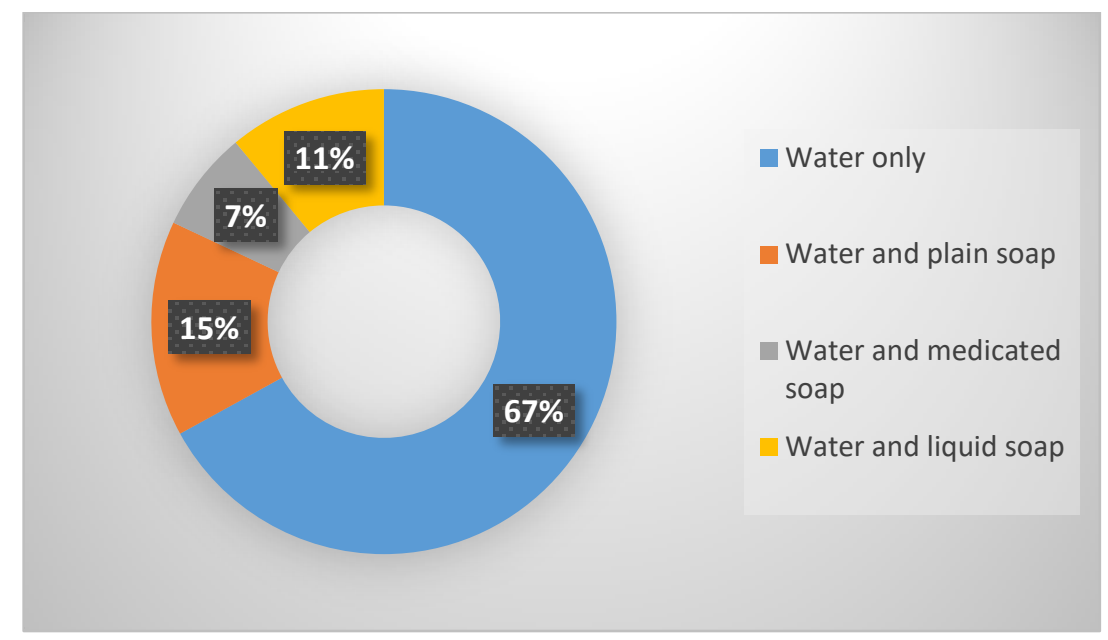

Figure 11: Washing of hands after defecating Source: Fieldwork, 2019

\subsection{Conclusions}

To ensure improvement in the water and sanitation situation of the inhabitants of a place, there is the need to understand their choice of water sources and sanitation systems as well as the factors that influence their choice. This study highlighted the importance of age, distance, culture, income level, occupation and educational qualification in choosing water sources and sanitation facilities by the households of the villages.

Distance was found to be the major factor preventing households from accessing improved water sources and as regards sanitation, cultural factors were found to play major role in the practice of open defecation in the villages. It is therefore important to step up campaigns aimed at behavioural change as a way through which the practice can be eliminated in the villages.

Water and sanitation are environmental issues to their very core, and together constitute one of the top drivers of development. Managing water supplies so they become neither depleted nor polluted, and providing good sanitation, are central to the health of communities and the environment on which they depend. Given the necessity of water and sanitation, the link between them and health, and the growing population, there is clearly a need that planning takes water and sanitation into consideration. Therefore, provision of a safe drinking water supply and sanitation should be an essential component of any plan that intends to guide the development of a community or region that aspires to achieving sustainable growth.

Based on the findings, the following recommendations are proffered:

- Ondo State government should endeavour to repair faulty public boreholes and construct water pipelines to the entire length and breadth of the villages to make sure safe drinking water is accessible from every part of the village in order to reduce the distance in getting safe drinking water

- Participation of the villages in the management and maintenance of the existing public boreholes will also go a long way in increasing their lifespan. A policy framework that will automatically bestow on the villages the responsibility for the ownership and management of newly constructed boreholes once completed should also be established

- Public enlightenment and programs on the awareness of health and environmental risks associated with unsafe water and poor sanitation as well as campaigns aimed at behavioural change should be organized in the villages regularly

- Provision of subsidized improved sanitation facilities by the Ondo State government to facilitate ownership of these facilities by the households 


\section{References}

Abubakar, I. R. (2017). Access to sanitation facilities among Nigerian households: determinants and sustainability implications. Sustainability, 9(547), pp. 1-17.

Abubakar, I. R. (2019). Factors influencing household access to drinking water in Nigeria. Utilities Policy, 58, pp. 40-51.

Aigbiremolen, A. O., E., A.-A. A., Nwadike, I., Afogbon, E., Airefetalor, I. A. and Oaikhena, O. I. (2018). Housing features and household access to sanitation facilities in a rural Nigerian community. Asian Pacific Journal of Health Sciences, 5(1), pp. 171-174.

Finelib.com Nigeria Directory and Search Engine. (2018). Ifedore Local Government Area Retrieved October 2, 2019, from Finelib Web: http://www.Finelib.com/listing/Ifedore-Local-GovernmentArea/62152/

Ishaku, H. T., Majid, M. R., Ajayi, A. P. and Haruna, A. (2011). Water supply dilemma in Nigerian rural communities: looking towards the sky for an answer. Journal of Water Resource and Protection, 3, pp. 598-606.

KAASHIF DEVELOPMENT INITIATIVES “Fighting Poverty, Improving lives" (2019). Retrieved from: http://kaashif.org/index.php?option=com_content\&view=article\&id=12\&ltemid=116

Lukman, S., Ismail, A., Asani, M. A., Bolorunduro, K. A., Foghi, P. U. and Oke, I. A. (2016). Effect of selected factors on water supply and access to safe. Ife Journal of Science, 18(3), pp. 623-639.

Novotný, J., Ficek, F., Hill, J. K. and Kumar, A. (2018). Social determinants of environmental health: A case of sanitation in rural Jharkhand. Science of the Total Environment, 643, pp. 762-774.

Olajuyigbe, A. E. and Fasakin, J. O. (2010). Citizens' Willingness to Pay for Improved Sustainable Water Supply in a Medium- Sized City in South Western Nigeria. Current Research Journal of Social Sciences, 2(2), pp. 41-50.

Ritchie, H and Roser, M. (2019). Our World in Data. Retrieved from https://ourworldindata.org/water-use-sanitation

Rotowa, O. O., Olujimi, J. A., Omole, F. K. and Olajuyigbe, A. E. (2015). Socioeconomic factors affecting household's sanitation preferences in Akure, Nigeria. European International Journal of Science and Technology, 4(5), pp. 183-194.

Sinha, A., Nagel, C., Schmidt, W., Torondel, B., Boisson, S., Routray, P., et al. (2018). Assessing patterns and determinants of latrine use in rural settings: A longitudinal study in Odisha, India. Science of the Total Environment, 643, pp. 762-774.

UNICEF/WHO. (2015). Progress on Sanitation and Drinking Water - 2015 Update and MDG Assessment. Geneva, Switzerland: WHO Library Cataloguing-in-Publication Data.

UN-Water. (2019). UN-Water. Retrieved from UN-Water Web site: https://www.unwater.org/waterfacts/water-sanitation-and-hygiene/

WHO/UNICEF. (2017). WHO/UNICEF. Retrieved August 10, 2019, from WHO/UNICEF Web site: http://washdata.org/monitoring/sanitation

WHO/UNICEF. (2019). WHO/UNICEF JMP. Retrieved August 28, 2019, from WHO/UNICEF Web site: http://washdata.org 
World Bank. (2001 ). Africa Rural Development Strategy - vision to action update . Washington D.C: World Bank Group.

\section{Cite this article as:}

Rotowa O. O. and Adeleye O. 2021. Water and Sanitation Situation in Selected Villages in Ifedore Local Government Area of Ondo State, Nigeria. Nigerian Journal of Environmental Sciences and Technology, 5(2), pp. 511-522. https://doi.org/10.36263/nijest.2021.02.0298 